\title{
The Use of Abciximab Associated with Primary Angioplasty for Treating Acute Myocardial Infarction
}

\author{
Manud Lisandro Hemández Bito, Nenton F. Stader de Souza Filho, Ávaro Veira Maura, \\ Luiz Augusto Lavalle, Rubens Zendbio Darwich, Marisa Leal, Eva Cantalejo Munhoz
}

Curitiba, PR - Brazil

\begin{abstract}
Objective - To assess the benefit resulting from the use of abciximab associated with primary angioplasty. The following parameters were analyzed in-hospital, at 30 days, and 6 months: (a) flow in the culprit artery; (b) ventricular function; (c) combined outcome of death, acute myocardial infarction, and aditional revascularization.
\end{abstract}

Methods - From November 1997 to June 1999, a longitudinal nonrandomized study with historical data of 137 patients with acute myocardial infarction within the first 12 hours. Patients undergoing primary angioplasty and were divided into 2 groups: those receiving (A) abciximab (26) or (B) conventional therapy (111). TIMI flow and regional ventricular function estimated by the standard deviation (SD)/ chordis index were analyzed.

Results - At the end of angioplasty, TIMI3flow was observed in $76.9 \%$ and $83.8 \%$ of the patients in groups $A$ and $B$, respectively $(P=0.58)$. In the reevaluation, patients with TIMI flow $<3$ showed a $100 \%$ improvement in group $A$ and a $33 \%$ in group $B(P<0.0001)$. A significant improvement $(P<0.0001)$ in regional ventricular function, by SD/chordis index, occurred in each group; no significant difference between groups however, was observed $(29.9 \% \times 20.2 \% ; P=0.58)$. A nonsignificant reduction in the combined outcome in the in-hospital phase $(3.85 \%$ A $\times 9.0 \% \mathrm{~B} ; \mathrm{P}=0.34)$ and on the $30^{\text {th }}$ day $(4.0 \% x$ $12.0 \% ; P=0.22$ ) was observed in group $A$.

Conclusion - Abciximab improved bloodflow. Primary angioplasty improved regional ventricular function independent of antithrombotic therapy. Abciximab showed a trend toward reducing the combined outcome in the inhospital phase and on the $30^{\text {th }}$ day.

Key words: primary angioplasty, abciximab, acute myocardial infarction

Centro de Diagnose Cardiovascular da Irmandade da Santa Casa de Misericórdia de Curitiba - UFPR - UFRGS - (PPG. Cardiologia)

Correspondência: Newton Fernando Stadler de Souza Filho - R. Anselmo Nicco, 70 Mossunguê - 81200-320 - Curitiba - Brazil - E-mail: newtonstadler@ uol. com.br English version by Stela Maris C. e Gandour
Myocardial ischemia is the major cause of cardiovascular mortality and morbidity in western societies, constituting a public health problem ${ }^{1-3}$. Coronary atherosclerosis is the major cause of acute myocardial infarction, in which a thrombotic process is associated with total obstruction of the coronary arteries in the first hours of infarction evolution, as shown in the angiographic studies by Dewood et $\mathrm{al}^{4}$. Later studies report that coronary thrombosis began with the rupture or fissure of atherosclerotic plaque, which, in most cases, did not cause severe stenosis ${ }^{5}$.

In the last 4 decades, a reduction in mortality due to acute myocardial infarction occurred as a result of the implementation of measures obtained through technological, pharmacological, and clinical advances. The 1970s and 1980s were known as the reperfusion era-initially, intracoronary thrombolysis and then intravenous thrombolysis ${ }^{6}$. Once the benefits of the intravenous thrombolytic therapy were shown in the GISSI study ${ }^{7}$, this therapy became the standard procedure for treating acute myocardial infarction. The ISIS- 2 trial $^{8}$ reported the use of acetylsalicylic acid associated with thrombolytic therapy contributing to a $23 \%$ reduction in the mortality of the patients treated with only acetylsalicylic acid, similar to that observed with the use of streptokinase, stressing the importance of the antiplatelet therapy. The GUSTO trial ${ }^{9}$ reported a reduction in mortality in the group treated with accelerated TPA associated with heparin as compared with that treated with streptokinase. The index for complete reperfusion, ie, TIMI 3 coronary flow, was also greater in the group treated with TPA than in the group treated with streptokinase (54\% versus $32 \%)^{10}$. Analyzing the relation between coronary artery patency and mortality, we observed that, independent of the therapy used, patients with TIMI 2 flow had a higher mortality than those with TIMI 3 flow (7.7\% versus $4.4 \%$ ). A correlation between the improvement in ventricular function and a reduction in mortality was also shown ${ }^{10}$.

Despite the benefits of pharmacological reperfusion confirmed in the randomized clinical trials, complications and limitations to its application exist. 
The limitation of thrombolytic therapy in reestablishing normal coronary artery flow may be explained by its prothrombotic effect ${ }^{11}$. After fibrin degradation in fibrinolytic therapy, the exposure of free thrombin automatically generates more thrombin, promoting platelet aggregation. This new platelet thrombus is resistant to fibrinolytic therapy and also secretes plasminogen activator inhibitor (PAI-1), which is a potent antagonist of fibrinolysis.

In the 1980s, mechanical reperfusion for the treatment of acute myocardial infarction was initiated with a large number of publications summarizing reports of experiences or case studies, and, later, of metaanalyses, indicating a very favorable trend toward the use of mechanical reperfusion as compared with pharmacological lysis. The first randomized PAMI study ${ }^{12}$ showed a $63 \%$ reduction in mortality in the group treated with primary angioplasty, compared with that treated with the thrombolytic agent ( $2.6 \%$ versus $6.5 \%$; $\mathrm{P}=0.06$ ); the risk of intracranial hemorrhage was lower in the group undergoing angioplasty. These benefits were maintained in the 2-year follow-up, with a lower incidence of recurring ischemia and revascularization of the target lesion, and also a reduction in the combined outcome of death and reinfarction ${ }^{13}$. Unquestionably, mechanical myocardial reperfusion through coronary angioplasty for treating acute myocardial infarction is currently an important alternative ${ }^{14}$. Despite all these advantages, major ischemic events have an incidence ranging from $5 \%$ to $15 \%$, and the repetition of the revascularization of the target lesion is required in $35 \%$ of the patients ${ }^{15}$.

Fibrin, thrombin, and platelets are key components in the formation of acute coronary artery thrombosis; this is the reason why, historically, anticoagulant therapies have played a fundamental role in the treatment of acute coronary syndromes. Until recently, anticoagulant therapy was mainly directed towards thrombin and fibrin, with less emphasis on platelets. But with the knowledge of coronary thrombosis pathophysiology, according to which platelets are the axis in initiating and propagating this process, more effective therapeutic interventions resulted. The role played by antiplatelet agents in medical practice was established with the experience with acetylsalicylic acid use ${ }^{8,16}$. But acetylsalicylic acid has a limited effect on platelet aggregation, inhibiting only the production of thromboxane A2, leaving the other pathways for platelet activation free. Recent advances have allowed the development of agents that are able to block the platelet glycoprotein (GP) IIb/IIIa receptor, which represents the final common pathway for platelet aggregation, providing a more effective inhibition independent of the activation pathway. Of the different blocking agents of the GP IIb/IIIa receptor, the most widely studied is the monoclonal antibody c7E3 or abciximab. Several randomized studies have shown, in different clinical situations, acute myocardial infarction inclusive, the benefits of the use of GP IIb/IIIa receptor inhibitors in reducing the incidence of ischemic events in patients undergoing coronary angioplasty ${ }^{15,17-19}$.

Recent studies ${ }^{20,21}$ showed better indices of complete reperfusion, ie, of TIMI 3 flow, with the use of abciximab in acute myocardial infarction, either associated with thrombolytic therapy or with primary angioplasty, with an improvement in ventricular function and a reduction in mortality.

In the present study, we analyzed the benefits of the use of abciximab associated with primary angioplasty for treating acute myocardial infarction. We assessed the following parameters in the in-hospital phase and in the 30day and 6-month follow-up: (a) the effect of the drug on the blood flow of the infarct-related coronary artery; (b) the effect of the drug on global and regional ventricular function; (c) the risk of major coronary events evaluated by the incidence of the combined outcome of death, acute myocardial infarction, and new revascularization of the target lesion.

\section{Methods}

From November 1997 to June 1999, 163 patients with the diagnosis of acute myocardial infarction and undergoing primary angioplasty were admitted to the hemodynamics service of the Centro de Diagnose Cardiovascular da Irmandade da Santa Casa de Misericórdia de Curitiba, Paraná state. A longitudinal nonrandomized study with historical data was designed.

For the diagnosis of acute myocardial infarction, at least 2 of the following criteria should be met: (a) typical precordial pain with a duration $>30$ minutes and $<12$ hours, with no relief with the use of vasodilator agents; (b) elevation of the ST segment on the electrocardiogram $>1 \mathrm{~mm}$, in at least 2 leads; (c) recent or presumably recent left bundlebranch block on the electrocardiogram; (d) total or partial occlusion of the coronary artery with the angiographic aspect of recent thrombus.

The exclusion criteria were the presence of cardiogenic shock and previous use of thrombolytic agents. The remaining 137 patients were divided into 2 groups as follows: group $\mathrm{A}-26$ patients receiving abciximab during the procedure and group $\mathrm{B}-111$ patients receiving the conventional therapy with primary angioplasty with no abciximab.

Before the interventional procedure, all patients received $300 \mathrm{mg}$ of acetylsalicylic acid orally and 10,000 units of heparin intravenously.

Implantation of stents at high pressure (between 10 and 20 atmospheres) depended on the technician's decision and was performed in accordance with the criteria published by Stone ${ }^{21}$.

The administration of abciximab was also decided by the technician, according to the criteria published by the RAPPORT investigators ${ }^{15}$.

After signing the written consent, the patients underwent coronary angiography with left ventriculography, which was diagnostic. Then, they underwent coronary angioplasty following the usual technique reported in several published studies and performed in all medical centers according to the protocol of the service. Stents 
were implanted in 18 patients $(69.3 \%$ ) of the abciximab group and in 55 (49.5\%) of the control group. In the 26 patients of group A, the platelet inhibitor was used during coronary angioplasty at the dosage of a bolus of $0.25 \mathrm{mg} / \mathrm{kg}$, followed by an infusion for 12 hours of $0.125 \mu \mathrm{g} / \mathrm{kg} / \mathrm{min}$ (maximum of $10 \mu \mathrm{g} / \mathrm{min}$ ). The drug was administered to all 26 patients after the first dilation with the balloon catheter.

After angioplasty, all patients were treated with the following drugs: (a) 200mg/day of oral acetylsalicylic acid; (b) $25-75 \mathrm{mg} /$ day of captopril; (c) $25-100 \mathrm{mg} /$ day of atenolol, when no contraindication to the use of $\beta$-blockers existed; (d) $250 \mathrm{mg}$ of ticlopidine twice a day, for 30 days in patients with an implanted stent.

The control group received 30,000 units/day of intravenous heparin in a continuous infusion for 24 to 48 hours.

The vascular sheath was removed 6 to 12 hours after the procedure with previous control of the activated clotting time.

An angiographic reevaluation was proposed to all patients prior to hospital discharge. Patients were discharged between the $4^{\text {th }}$ and $10^{\text {th }}$ day of hospitalization.

Clinical data obtained during hospitalization were entered into the database and evaluated through retrospective analysis of patients' medical records. The patients were reassessed at 30 days and 6 months through telephone contact or review of their medical records, or both.

During the in-hospital phase, we analyzed the combined outcome of death due to any cause and new revascularization of the culprit coronary artery, either by angioplasty or surgery.

The incidence of reocclusion was also analyzed. The patients with coronary reocclusion who underwent new angioplasty or surgery were considered only in the outcome of new revascularization for the analysis of the combined outcome.

In the follow-ups at 30 days and 6 months, we considered the combined outcome of: (a) death due to any cause; (b) nonfatal acute myocardial infarction; (c) new revascularization of the culprit coronary artery, either by angioplasty or surgery.

The hemorrhagic complications were classified as major, minor, or insignificant bleeding, according to the criteria of the TIMI study ${ }^{22}$.

Blood flow reestablishment (TIMI 2 or 3 ) in the culprit coronary artery by the end of the procedure was considered angiographic success. The patient's hospital discharge was considered clinical success.

The digital images of coronary angiography and ventriculography obtained with the Integris 3000 scanner (Philips) were recorded on a compact disk and later analyzed off-line by a single technician, using the MedView program (Medcon Ltd. Telemedicine Technology). In case of doubt in the analysis of degree of coronary flow, 2 more interventional cardiologists were consulted.

Coronary flow was analyzed using the classification reported in the phase I TIMI study ${ }^{23}$ in the 3 following stages: in the initial angiography (initial TIMI), at the end of angioplasty (final TIMI), and at reevaluation (reevaluation TIMI), and with previous intracoronary administration of $10 \mathrm{mg}$ to $20 \mathrm{mg}$ of isosorbide mononitrate. Analysis of quantitative coronary angiography was performed using the edge-detection method ${ }^{24}$.

Ventricular function in the acute phase of infarction and at reevaluation was analyzed in a paired way. Global ventricular function was calculated according to the arealongitude method ${ }^{25}$ and regional ventricular function according to the centerline method ${ }^{26}$. In the infarct-related region, the mean of the contiguous hypokinetic cords, expressed as SD/chordis, was calculated, and the wall mobility index and the number of hypokinetic cords within the region of interest were determined.

A descriptive analysis of data was performed with tables, charts, and graphs. The continuous variables were expressed as mean $\pm \mathrm{SD}$ or median. The discreet variables were expressed as percentage and count.

Tests of comparison of 2 proportions, such as the parametric Student $t$ test and the nonparametric MannWhitney test (through the Primer of the Biostatistic program), were used. For independent samples, the chi-square test with Yates correction for continuity and Fisher exact test (through the Epi-Info program) were used. For related samples, the paired Student $t$ test and the nonparametric Wilcoxon test were used. The minimum significance level adopted was $5 \%$.

\section{Results}

We analyzed 137 consecutive patients undergoing primary angioplasty for acute myocardial infarction. They were divided into 2 groups as follows: 26 patients receiving the GP IIb/IIIa inhibitor, abciximab, during the intervention (abciximab group) and 111 patients undergoing the conventional treatment after primary angioplasty (control group). Both groups were homogeneous in baseline demographic, clinical (tab. I), and angiographic (tab. II) characteristics.

The time elapsed from the patient's arrival at the hospital to recanalization of the artery ranged from 15 to 120 minutes for both groups (median of 35 minutes in the abciximab group, and 34 minutes in the control group; $\mathrm{P}=0.418$ ).

In $3(2.7 \%)$ control group patients, impairment of the trunk of the left coronary artery occurred.

Stent implantation was more frequent, but nonsignificant, in the abciximab group $(69.2 \% \times 49.5 \%, \mathrm{P}=0.11)$.

No major bleeding occurred in the groups. The incidence of minor bleeding was slightly higher in the abciximab group (11.5\%) than in the control group (10.8\%), but with no significant difference $(\mathrm{P}=0.944)$. In 1 patient ( $3.8 \%)$, the abciximab infusion had to be suspended because the patient had a hematoma in the left arm after puncture for a blood test. No patient required repositioning of blood derivatives. The median of the activated clotting time was 325 seconds in the abciximab group and 313 seconds in the control group, with no significant difference. 


\begin{tabular}{|c|c|c|c|c|}
\hline & $\begin{array}{l}\text { Abciximab } \\
(\mathrm{n}=26)\end{array}$ & $\begin{array}{l}\text { Control } \\
(\mathrm{n}=111)\end{array}$ & $\mathrm{p}$ & \\
\hline Age (years) & $57.3 \pm 12.8$ & $59.0 \pm 11.8$ & 0.775 & NS \\
\hline Male & $76.9 \%(20)$ & $74.8 \%(83)$ & 0.980 & NS \\
\hline Female & $23.1 \%(6)$ & $25.2 \%(28)$ & 0.980 & NS \\
\hline \multicolumn{5}{|l|}{ Risk factors } \\
\hline Arterial hypertension & $46.2 \%(12)$ & $0.5 \%(45)$ & 0.757 & NS \\
\hline Diabetes mellitus & $15.4 \%(4)$ & $0.8 \%(12)$ & 0.750 & NS \\
\hline Smoking & $30.8 \%(8)$ & $39.6 \%(44)$ & 0.543 & NS \\
\hline Cholesterol & $30.8 \%(8)$ & $27.0 \%(30)$ & 0.884 & NS \\
\hline Familial history & $26.9 \%(7)$ & $6.9 \%(41)$ & 0.463 & NS \\
\hline \multicolumn{5}{|c|}{ Cardiovascular antecedents } \\
\hline Previous surgery & $3.8 \%(1)$ & $0.0 \%(0)$ & 0.439 & NS \\
\hline Previous PCA & $11.5 \%(3)$ & $4.5 \%(5)$ & 0.365 & NS \\
\hline $\begin{array}{l}\text { Previous myocardial } \\
\text { infarction }\end{array}$ & $7.7 \%(2)$ & $8.1 \%(9)$ & 0.739 & NS \\
\hline \multicolumn{5}{|l|}{ Killip-Kimball class } \\
\hline I & $73.1 \%(19)$ & $55.0 \%(61)$ & 0.184 & NS \\
\hline II & $7.7 \%(2)$ & $27.9 \%(31)$ & 0.184 & NS \\
\hline $\mathrm{I}+\mathrm{II}$ & $80.8 \%(21)$ & $82.9 \%(92)$ & 0.974 & NS \\
\hline III & $11.5 \%(3)$ & $10.8 \%(12)$ & 0.806 & NS \\
\hline Not classified & $7.7 \%(2)$ & $6.3 \%(7)$ & 0.857 & NS \\
\hline $\begin{array}{l}\text { Time pain/ } \\
\text { recanalization (min) }\end{array}$ & $\begin{array}{l}277.7 \pm 153.5 \\
\quad 256^{*}\end{array}$ & $\begin{array}{c}296.6 \pm 146.5 \\
270^{*}\end{array}$ & 0.418 & NS \\
\hline CPK peak value & $961.1 \pm 155.1$ & $930.7 \pm 198.6$ & 0.746 & NS \\
\hline
\end{tabular}

\begin{tabular}{|c|c|c|c|c|}
\hline \multicolumn{5}{|c|}{ Table II - Angiographic characteristics } \\
\hline \multicolumn{2}{|r|}{ Abciximab (n=26) } & \multirow{2}{*}{$\begin{array}{c}\text { Control }(\mathrm{n}=111) \\
55.9 \%(62)\end{array}$} & \multicolumn{2}{|l|}{$\mathrm{p}$} \\
\hline Multiarterial & $42.3 \%(11)$ & & 0.302 & NS \\
\hline Stent implantation & $69.2 \%(18)$ & $49.5 \%(55)$ & 0.111 & NS \\
\hline \multicolumn{5}{|l|}{ Culprit vessel } \\
\hline $\mathrm{AD}$ & $34.6 \%(9)$ & $44.2 \%(49)$ & 0.502 & NS \\
\hline $\mathrm{RC}$ & $57.7 \%(15)$ & $40.5 \%(45)$ & 0.170 & NS \\
\hline $\mathrm{Cx}$ & $3.8 \%(1)$ & $10.8 \%(12)$ & 0.468 & NS \\
\hline Dg & $0.0 \%(0)$ & $4.5 \%(5)$ & 0.603 & NS \\
\hline Saphenous & $3.8 \%(1)$ & $0.0 \%(0)$ & 0.414 & NS \\
\hline \multicolumn{5}{|l|}{ Infarcted wall } \\
\hline Anterior & $38.5 \%(10)$ & $46.9 \%(52)$ & 0.578 & NS \\
\hline Inferior & $57.7 \%(15)$ & $45.0 \%(50)$ & 0.343 & NS \\
\hline Lateral & $3.8 \%(1)$ & $8.1 \%(9)$ & 0.734 & NS \\
\hline \multicolumn{5}{|l|}{ Type of lesion } \\
\hline B1 & $30.8 \%(8)$ & $27.9 \%(31)$ & 0.789 & NS \\
\hline B2 & $61.5 \%(16)$ & $67.6 \%(75)$ & 0.858 & NS \\
\hline $\mathrm{C}$ & $7.7 \%(2)$ & $4.5 \%(5)$ & 0.795 & NS \\
\hline \multicolumn{2}{|c|}{ Collateral circulation $30.8 \%$ (8) } & $36.0 \%(40)$ & 0.786 & NS \\
\hline \multicolumn{2}{|c|}{ Ejection fraction (\%) $55.5 \pm 15$} & $53.3 \pm 13.7$ & 0.723 & NS \\
\hline $\begin{array}{l}\text { AD- anterior descer } \\
\text { circumflex coron } \\
\text { nonsignificant. }\end{array}$ & $\begin{array}{l}\text { nding coronary art } \\
\text { ary artery; Dg- }\end{array}$ & $\begin{array}{l}\text { ery; RC- right coror } \\
\text { diagonal coronar }\end{array}$ & $\begin{array}{l}\text { aary arte } \\
\mathrm{y} \text { arter }\end{array}$ & $\begin{array}{l}\mathrm{y} ; \mathrm{Cx}- \\
\text {; NS }\end{array}$ \\
\hline
\end{tabular}

Angiographic success was observed in $100 \%$ of the patients in the abciximab group and in $97.3 \%$ of the patients in the control group $(\mathrm{P}=0.529)$.

Angiographic reevaluation was performed in 25 (96.1\%) patients in the abciximab group and in $89(80.2 \%)$ patients in the control group $(\mathrm{P}=0.076)$. In the abciximab group, $1(3.9 \%)$ patient refused to undergo reevaluation. In the control group, $22(19.8 \%)$ patients did not undergo reevaluation due to the following reasons: (a) severe peripheral arterial insufficiency in 2 patients; (b) associated critical lesion of the trunk of the left coronary artery in 3 patients; (c) death in 4 patients; (d) reocclusion and new angioplasty in 3 patients; (e) hemodynamic instability in 1 patient; (f) 1 patient left the hospital; (g) patient's or clinical cardiologist's refusal in 8 cases.

The mean time of reevaluation was $4.7 \pm 1.3$ days for the abciximab group and $4.8 \pm 1.8$ days for the control group $(\mathrm{P}=0.716)$.

In the coronary flow analysis during initial angiography, TIMI 0 flow was observed in $69.2 \%$ of the patients in the abciximab group and in $78.4 \%$ of those in the control group ( $\mathrm{P}=0.342)$; TIMI 1 flow was observed in $7.7 \%$ and 9.9\% of the patients in the abciximab and control groups, respectively $(\mathrm{P}=0.785)$. The abciximab group had a higher index of TIMI 2 flow at hospital admission as compared with that of the control group ( $23.1 \%$ versus $10.8 \%$ ); this difference, however, was not statistically significant $(\mathrm{P}=0.235)$. Only $1(0.9 \%)$ patient in the control group had TIMI 3 flow on the first angiography.

At the end of the procedure, coronary flow was assessed, with previous administration of intracoronary vasodilator. TIMI 3 flow was observed in $76.9 \%$ of the patients in the abciximab group and in $83.8 \%$ of the patients in the control group, with no significant difference ( $\mathrm{P}=0.585)$; TIMI 2 flow was observed in $23.1 \%$ and $13.5 \%$ of the patients in the abciximab and control groups, respectively $(\mathrm{P}=0.387)$. No patient in the abciximab group had TIMI 0 flow or TIMI 1 flow at the end of the procedure; 3 (2.7\%) patients in the control group, however, had TIMI 1 flow.

In the abciximab group, of the $25(96.2 \%)$ patients undergoing angiographic reevaluation, all had TIMI 3 flow. In the control group, of the $89(80.2 \%)$ patients undergoing angiographic reevaluation, TIMI 3 flow was observed in $92.1 \%$ and TIMI 2 flow in $6.7 \%$. One (1.1\%) patient had total occlusion (TIMI 0 flow) on reevaluation, with no clinical, biochemical, or electrocardiographic suspicion of reocclusion; this patient underwent elective revascularization surgery during the same hospitalization because of associated coronary artery lesions.

Patients with TIMI flow $<3$ at the end of angioplasty were analyzed. In the abciximab group, of the 6 patients with final TIMI flow lower than grade 3, all (100\%) had TIMI 3 flow on the angiographic reevaluation. In the control group, of the 18 patients with TIMI flow $<3$, only $6(33 \%)$ patients had an improvement in coronary flow on the angiographic reevaluation; this difference was statistically significant $(\mathrm{P}<0.0001)$ (fig. 1). Of the remaining 12 patients in the control group, 6 remained with the same grade of TIMI flow; 3 died; 1 had worsening of the flow with reocclusion; and 2 were not reevaluated.

In the abciximab group, $83.3 \%$ of the patients undergoing stent implantation had TIMI 3 flow; on the other hand, $62.5 \%$ of the patients treated with simple balloon angioplasty had TIMI 3 flow ( $\mathrm{P}=0.33$ ). In the control group, 


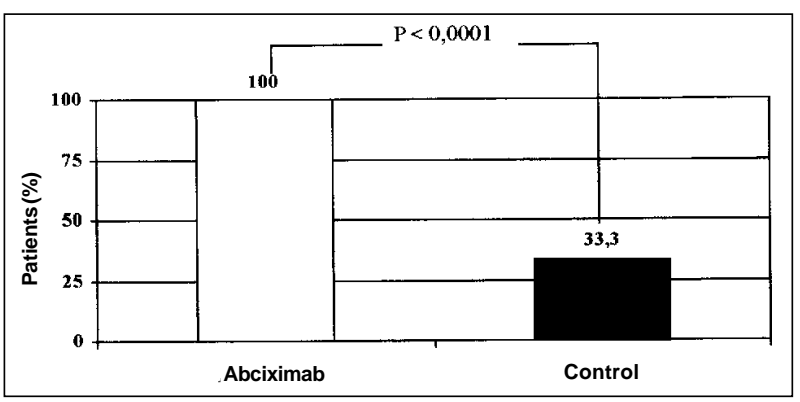

Fig. 1 - Improvement in the coronary artery flow in the reevaluation of patients with final TIMI flow $<3$

a nonsignificant reduction in the TIMI 3 flow index was observed in patients undergoing stent implantation as compared with those treated with angioplasty $(76.4 \%$ versus $91.1 \%$, respectively; $\mathrm{P}=0.065$ ).

In the angiographic analysis, both groups were homogeneous in regard to the size of the vessel, the final minimum luminal diameter, and the percentage of residual stenosis in the segment treated (tab. III).

Ventriculographies of the acute phase and of the angiographic reevaluation were obtained in 25 patients in the abciximab group and in 89 patients in the control group. In the abciximab group, global ejection fraction showed a nonsignificant improvement of $3.3 \%$; in the control group, this improvement was $5.6 \%(\mathrm{P}<0.0001)$. Mobility of the infarcted wall, estimated using the $\mathrm{SD} /$ chordis index,

\begin{tabular}{|lcccc|}
\hline \multicolumn{5}{|c|}{ Table III - Quantitative coronary angiography } \\
\hline QCA & Abciximab (n=26) & Control $(\mathrm{n}=111)$ & $\mathrm{p}$ & \\
\hline Initial MLD (mm) & $0.21 \pm 0.42$ & $0.12 \pm 0.25$ & 0.195 & $\mathrm{NS}$ \\
Initial \% STE & $93.7 \pm 13.1$ & $96.2 \pm 8.2$ & 0.635 & $\mathrm{NS}$ \\
RfD (mm) & $3.36 \pm 0.68$ & $3.28 \pm 0.61$ & 0.850 & $\mathrm{NS}$ \\
Final MLD (mm) & $2.92 \pm 0.77$ & $2.83 \pm 0.69$ & 0.763 & $\mathrm{NS}$ \\
Residual \% STE & $14.0 \pm 8.4$ & $14.6 \pm 8.8$ & 0.818 & $\mathrm{NS}$ \\
\hline
\end{tabular}

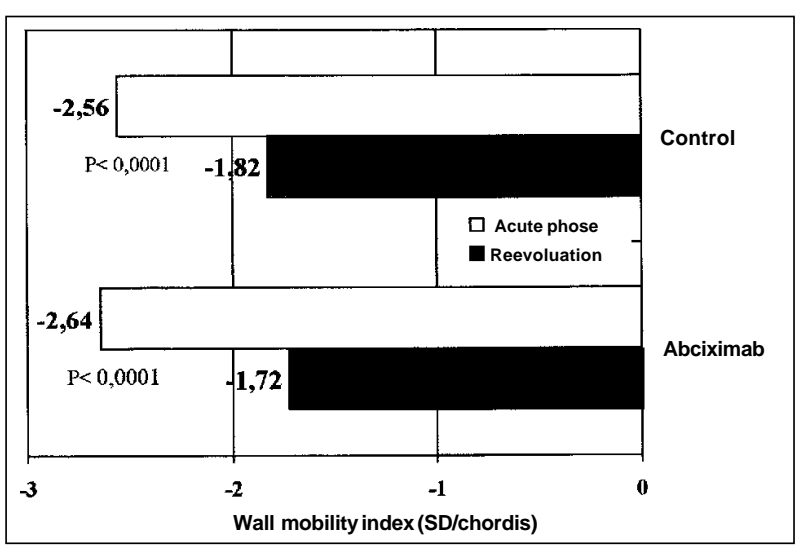

Fig. 2 - Paired analysis of the regional ventricular function. Wall mobility index.

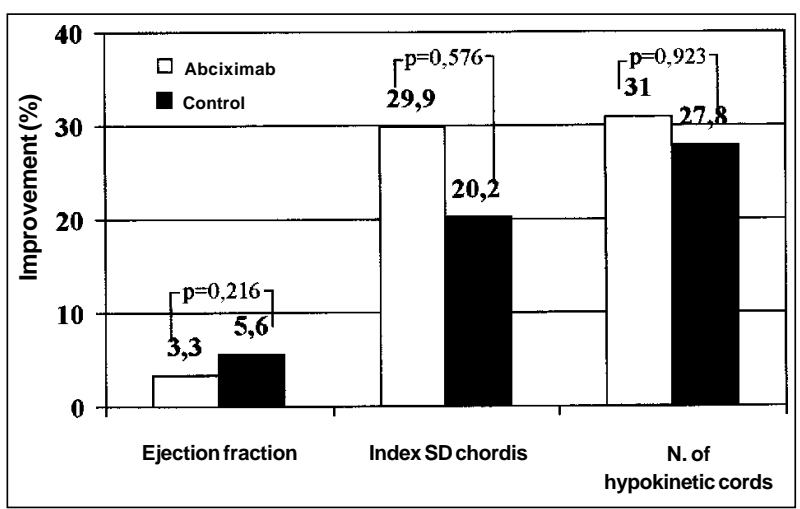

Fig. 3 - Improvement in the global and regional ventricular function (percentage variation).

showed a significant improvement of $29.9 \%$ in the abciximab group and of $20.2 \%$ in the control group (figs. 2 and 3 ). In the abciximab group, the number of hypokinetic cords showed a significant reduction of $31 \%$; in the control group, this reduction was $27.8 \%$ (fig. 3). When comparing the groups, no significant difference in the global ejection fraction, in the $\mathrm{SD} /$ chordis index, and in the number of hypokinetic cords was observed (fig. 3).

Clinical success was observed in $100 \%$ of the patients in the abciximab group and in $96.4 \%$ of those in the control group $(\mathrm{P}=0.426)$. The mean hospital stay was $5.7 \pm 1.2$ days for the abciximab group, and $6.9 \pm 5.2$ (median of 6 ) days for the control group, with no significant difference. Clinical follow-up was performed in $125(91.2 \%)$ patients, $25(96.2 \%)$ patients in the abciximab group and $100(90.1 \%)$ patients in the control group.

In the in-hospital phase, a nonsignificant reduction in the incidence of the combined outcome of death and new revascularization of the culprit coronary artery was observed in the abciximab group as compared with that in the control group (tab. IV, fig. 4). No revascularization surgery occurred on an emergency basis in either group.

The patients treated with abciximab showed a nonsignificant reduction in the combined outcome of death, infarction, and revascularization of the culprit artery in the 30-day follow-up (tab. IV, fig. 4). In the 6-month follow-up, no difference in the incidence of the combined outcome of death, infarction, and revascularization (24\% in the abciximab group and $22 \%$ in the control group; $\mathrm{P}=0.996$ ) was observed (tab. IV, fig. 4).

Mortality and the incidence of revascularization of the culprit artery were similar for both groups. Myocardial infarction was more frequent, but not significant, in the abciximab group than in the control group (tab. IV).

\section{Discussion}

In this study, the use of abciximab showed a significant improvement in the blood flow in the infarct-related coronary artery, and this was evident in the angiographic reevaluation. Mobility of the infarcted wall, which was 


\begin{tabular}{|c|c|c|c|c|}
\hline \multicolumn{5}{|c|}{ Table IV - Major cardiac events } \\
\hline In-hospital phase & $\begin{array}{l}\text { Abciximab } \\
(\mathrm{n}=26)\end{array}$ & $\begin{array}{l}\text { Control } \\
(\mathrm{n}=111)\end{array}$ & $\mathrm{p}$ & \\
\hline $\begin{array}{l}\text { Combined outcome } \\
\text { (death, revascularization) }\end{array}$ & $3.85 \%(1)$ & $9.0 \%(10)$ & 0.342 & NS \\
\hline Death & 0 & $3.6 \%(4)$ & 0.738 & NS \\
\hline Revascularization & $3.85 \%(1)$ & $5.4 \%(6)$ & 0.872 & NS \\
\hline Reocclusion & $3.85 \%(1)$ & $3.6 \%(4)$ & 1.0 & NS \\
\hline 30 days & $(\mathrm{n}=25)$ & $(\mathrm{n}=100)$ & & \\
\hline $\begin{array}{l}\text { Combined outcome (death, } \\
\text { revascularization, AMI) }\end{array}$ & $4.0 \%(1)$ & $12.0 \%(12)$ & 0.217 & NS \\
\hline Death & 0 & $5.0 \%(5)$ & 0.445 & NS \\
\hline Revascularization & $4.0 \%(1)$ & $6.0 \%(6)$ & 0.889 & NS \\
\hline AMI & 0 & $1.0 \%(1)$ & 0.800 & NS \\
\hline 6 months & $(n=25)$ & $(\mathrm{n}=100)$ & & \\
\hline Desfecho composto & $24.0 \%(6)$ & $22.0 \%(22)$ & 0.996 & NS \\
\hline Death & $8.0 \%(2)$ & $9.0 \%(9)$ & 0.795 & NS \\
\hline Revascularization & $12.0 \%(3)$ & $13.0 \%(13)$ & 0.878 & NS \\
\hline AMI & $4.0 \%(1)$ & $2.0 \%(2)$ & 0.491 & NS \\
\hline
\end{tabular}

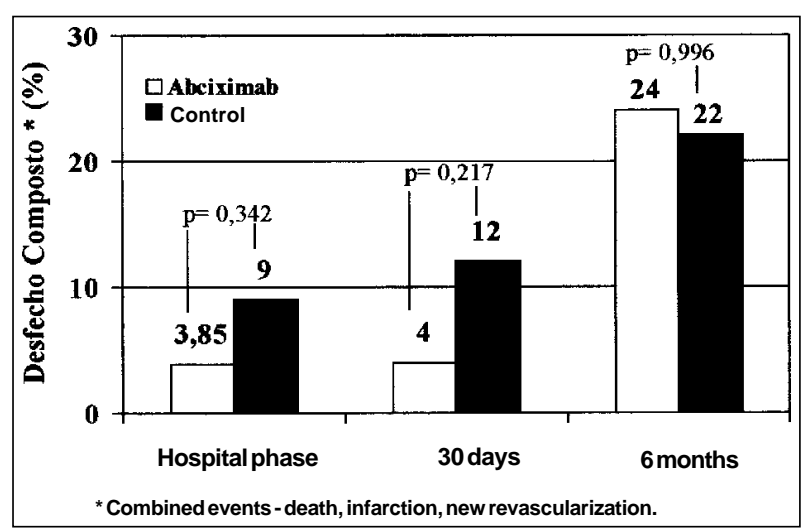

Fig. 4 - Major coronary events in the in-hospital phase, at 30 days, and 6 months. *Combined events - death, infarction, new revascularization.

estimated using the SD/chordis index, showed a greater improvement with the use of abciximab, even though the difference between the groups was not significant. The patients treated with abciximab showed a nonsignificant reduction in the combined outcome of death, infarction, and revascularization of the target lesion in the in-hospital phase and at the $30^{\text {th }}$ day of follow-up. In the 6-month follow-up, no difference was observed in the combined outcome.

The importance of reestablishing complete coronary flow, ie, TIMI 3 flow, and the relation of the flow obtained with the ventricular function and clinical evolution of the patients has been stressed in recent studies. The clinical benefits of the recanalization of the infarct-related coronary artery depend on the grade of the blood flow obtained. Several studies have shown that patients with TIMI 2 flow, ie, with arterial patency, but not complete reperfusion, have an evolution similar to that of patients with an occluded artery ${ }^{27}$. The relation between coronary flow and ventricular function was shown in the GUSTO study ${ }^{9}$, in which patients with TIMI 2 flow in the culprit artery had more impaired ventricular function and higher mortality than patients with normal coronary flow or TIMI 3 flow ${ }^{10}$.

Primary angioplasty has shown a higher complete reperfusion index (TIMI 3 flow) as compared with that of the thrombolytic therapy ${ }^{10,12,23,28}$.

In our analysis, we observed a satisfactory TIMI 3 flow index for both groups $(77 \%$ and $84 \%$ for the abciximab and control groups, respectively). The lower incidence of TIMI 3 flow in the abciximab group could not be explained by the larger number of stents implanted in this group, in accordance with other studies ${ }^{29}$, because the patients in the abciximab group undergoing stent implantation had a higher TIMI 3 flow index than those treated only with the balloon ( $83 \%$ versus $62 \%$, respectively; $\mathrm{P}=0.33$ ). On the other hand, in the control group, we observed that stent implantation determined a tendency towards a reduction in the TIMI 3 flow index (76\% with stent versus $91 \%$ without stent, $\mathrm{P}=0.065$ ), suggesting that abciximab could have changed this situation, in accordance with the CADILLAC study $^{21}$. This lower incidence of TIMI 3 flow in the abciximab group as compared with that in the control group and with the results of other studies may have been due to the way the drug was administered. Contrary to other studies, in which abciximab was administered at the beginning of the procedure, in our case series, the drug was administered during angioplasty, after the first balloon dilation. In some cases, it was even initiated at the end of the procedure, and, therefore, without time enough to observe the maximum effect of the drug and to cause lysis of the distal microthrombi ${ }^{30-32}$, with an improvement in coronary flow. However, the benefit of abciximab was evident on the angiographic reevaluation, in which all patients of the abciximab group with impairment in coronary flow by the end of angioplasty showed complete flow improvement. In the control group, however, only $33 \%$ of the patients showed improvement. In addition, of the 12 patients in the control group who had no flow improvement on reevaluation, 4 (33\%) experienced adverse coronary events in the in-hospital phase.

Recent studies, however, suggest that the presence of TIMI 3 flow in the infarct-related coronary artery does not necessarily mean successful myocardial reperfusion ${ }^{33}$. Contrast echocardiography has shown that, despite the presence of normal epicardial flow after primary angioplasty, some patients have impaired myocardial perfusion associated with a poor recovery in ventricular function ${ }^{34-36}$. Neumann et $\mathrm{al}^{37}$ reported that patients receiving abciximab had an improvement in coronary flow in the intracoronary Doppler assessment as compared with those in the group conventionally treated, and that this difference did not relate to the degree of coronary patency obtained. The authors concluded that abciximab should have improved microvascular perfusion, determining improvement in ventricular function, mainly in the regional mobility of the impaired wall.

In the present study, in the analysis of global ventricular function through calculation of the ejection fraction, a mild improvement was observed in both groups (3.3\% in the abciximab group and $5.6 \%$ in the control group). However, a 
number of studies have reported limitations in the use of the global ejection fraction for analyzing and comparing different thrombolytic therapies ${ }^{26,38}$.

In the paired analysis of the regional ventricular function, we observed a significant improvement in the SD/ chordis index for both groups, but more important in the abciximab group ( $29.9 \%$ versus $20.2 \%$ ), resulting in a relative $48 \%$ increase as compared with that in the control group. However, when comparing the groups, this difference did not reach statistical significance. The number of hypokinetic cords also showed a decrease in both groups, and the difference between the groups was only $3 \%$ in favor of the abciximab group, but with no statistical significance. The centerline method was more sensitive for assessing the regional mobility of the wall, reflecting the function of the ischemic and nonischemic myocardium ${ }^{25}$. Sheehan et al $^{26}$ showed that the severity of hypokinesia, assessed by the $\mathrm{SD} /$ chordis index, correlated better with the size of the infarct (estimated by the release of CPK) than with the ejection fraction.

The improvement in coronary flow observed in the patients in the abciximab group, as well as a greater reduction in the hypokinesia of the infarcted wall, may better explain the improvement in microvascular perfusion with the use of abciximab, as already shown in previous studies ${ }^{32,37}$.

A greater number of patients in the control group did not undergo angiographic reevaluation, but the difference was not statistically significant. In $1 / 3$ of these patients, the reason for not undergoing reevaluation was the presence of some adverse cardiac events in the in-hospital phase.

Even though this study did not have enough value to detect a significant difference between the 2 treatment regimens in the clinical evolution of the patients, adverse coronary events in the in-hospital phase and in the first 30 days were much less frequent in the abciximab group than in the control group. In the in-hospital phase, a 57\% reduction was observed in the incidence of the combined outcome of death and revascularization of the target lesion with the use of abciximab ( $3.85 \%$ versus $9.0 \%$; $=0.342)$. In the 30-day follow-up, the reduction in the combined outcome of death, infarction, and revascularization of the target lesion was $66.6 \%$ (4\% versus $12 \% ; \mathrm{P}=0.217$ ).

The initial reduction in the adverse coronary events was not maintained in the 6-month follow-up (24\% in the abciximab group and $22 \%$ in the control group; $\mathrm{P}=0.996$ ).

In-hospital mortality in the total group was $2.9 \%$, no death being observed in the abciximab group. In the control group, $4(3.6 \%)$ deaths occurred, and 2 patients showed TIMI 1 flow at the end of angioplasty, possibly due to microembolization of the distal bed.

The incidence of adverse coronary events shown in this series, as well as the reduction in these events observed with the use of abciximab, is similar to that reported in the RAPPORT $^{15}$ and other studies ${ }^{37,39,40}$.
In this series, no major bleeding and no need for transfusion were observed. In addition, a low incidence of minor hemorrhagic complications occurred, suggesting that the use of abciximab is safe.

Considering that a larger number of patients with stent implantation was observed in the abciximab group than in the control group $(69.2 \%$ versus $49.5 \%$; $\mathrm{P}=0.111)$ and that the use of stents has been shown to reduce the incidence of ischemic events in primary angioplasty ${ }^{41}$, this might have influenced the favorable results observed in the abciximab group. However, analyzing the patients in the control group who experienced adverse coronary events in the first 30 days, we observed that $50 \%$ had undergone stent implantation, and that, of the 5 deaths observed, 4 occurred in patients who received stents. In addition, the only adverse ischemic event observed in the abciximab group also occurred in a patient who had undergone stent implantation. These data suggest that the benefits observed occurred due to the use of abciximab.

An important limitation of this study was the small sample size analyzed, mainly the group treated with abciximab. The good results observed in this group might have occurred by chance, because the sample did not have enough statistical power to detect differences in some of the observations. Our results, however, are similar to those published in the literature.

Both groups were homogeneous in general characteristics, and no apparent variable that could interfere with the results existed; the small number of patients, however, mainly in the group treated, could compromise this homogeneity between the groups. Another limitation of this study was that the analysis of quantitative coronary angiography and that of ventricular function was performed by a single technician, even though the angiographic analysis was performed with no knowledge of the therapy used to minimize the technician's interference.

The fact that this is not a randomized study certainly constitutes its major limitation. The design of a randomized study with a larger number of patients could eliminate these limitations and establish a more significant association between the use of abciximab and its benefits.

In conclusion, the use of abciximab in primary angioplasty improved blood flow in the infarct-related coronary artery, even when it was administered at the beginning of the procedure. Primary angioplasty allowed a significant improvement in the regional function of the left ventricle in the infarct-related area, independent of the antithrombotic therapy used. This improvement was more marked with the use of abciximab, even though the difference between the groups was not significant. The use of abciximab in primary angioplasty showed a tendency towards a reduction in the incidence of adverse coronary events (death, myocardial infarction, and new revascularization of the culprit artery) in the first 30 days. 


\section{References}

1. Yellon DM, Rahimtoola SH, Opie LH. Nuevos Síndromes Isquémicos. 1ª Ed. Barcelona: J\&CEdiciones Médicas S. L., 1998.

2. Leite RS, Rodrigues L, Gottschall C. Inibidores da glicoproteína IIb/IIIa: atualização. Rev Bras Cardiol Invas 1998; 6: 40-6.

3. Antman EM, Braunwald E. Acute myocardial infarction. In: Braunwald E. Heart Disease: A Textbook of Cardiovascular Medicine. $5^{\text {th }}$. ed. Philadelphia: WB Saunders Co., 1997: 1184-288.

4. Dewod MA, Spores J, Notske R, et al. Prevalence of total coronary occlusion during the early hours of transluminal myocardial infarction. N Eng J Med 1980; 303: 897-902.

5. Davies MJ. A macro and micro view of coronary vascular insult in ischemic heart disease. Circulation 1990; 82(suppl II): II-38-II-46.

6. Rentrop KP, Blanke H, Karsch KR. Initial experience with transluminal recanalization of the recently occluded infarc-related coronary artery in acute myocardial infarction: comparison with conventionally treated patients. Clin Cardiol 1979; 2: 92-105

7. Gruppo Italiano Per Lo Studio Della Streptochinasi Nell'infarto Miocardico (GISSI). Effectiveness of intravenous thrombolytic treatment in acute myocardial infarction. Lancet 1986; 1: 397-401.

8. ISIS-2 Second International Study of Infract Survival collaborative group. Randomized trial of intravenous streptokinase, oral aspirin, both, or neither among 17.187 cases of suspected acute myocardial infarction: ISIS-2. Lancet 1988; 2 $349-60$.

9. The GUSTO Investigators. An international randomized trial comparing four thrombolytic strategies for acute myocardial infarction. NEng J Med 1993; 329: 673-82.

10. The GUSTO Angiographic Investigators. The effects of tissue plasminogen activator, streptokinase, or both on coronary-artery patency, vetricular function, and survival after acute myocardial infarction. N Eng J Med 1993; 329: 1615-22.

11. TopolE. Toward a new frontier in myocardial reperfusion therapy: emerging platelet preeminence. Circulation 1998; 97: 211-18.

12. Grines CL, Browne KF, Marco J, et al. A comparison of immediate angioplasty thrombolytic therapy for acute myocardial infarction. N Eng J Med 1993; 328: 673-9.

13. Nunn CM, O'Neill WW, Rothbaum D. Long-term outcome after primary angioplasty: report from the Primary Angioplasty in Myocardial Infarction (PAMI-I) trial. J Am Coll Cardiol 1999; 33: 640-6

14. Ryam TJ, Antman EM, Brooks NH, and the ACC/AHA Task Force. 1999 update: ACC/AHA guidelines for the management of patients with acute myocardial infarction: executive summary and recommendations: A report of the American College of Cardiology/American Heart Association TasK Force on practice guidelines (committee on management of acute myocardial infarction). Circulation 1999; 100: 1016-30.

15. Brener SJ, Barr LA, Burchenal JEB, et al. Randomized, placebo-controlled trial of platelet glycoprotein IIb/IIIa blockade with primary angioplasty for acute myocardial infarction: ReoPro and prymary PTCA organization and randomized trial (RAPPORT) investigators. Circulation 1998; 98: 734-41.

16. Théroux P, Ouimet H, McCans J, et al. Aspirin, heparin or both to treat acute unstable angina. N Engl J Med 1988; 319: 1105-111.

17. The EPIC Investigators. Use of a monoclonal antibody directed against the platelet glycoprotein IIb/IIIa receptor in high-risk coronary angioplasty. $\mathrm{N}$ Engl J Med 1994; 330: 956-61.

18. The EPILOG Investigators, Platelet glycoprotein IIb/IIIa receptor blockade and low-dose heparin during percutaneous coronary revascularization. N Engl J Med 1997; 336: 1689-96.

19. The CAPTURE Investigators, Randomized placebo-controlled trial of abciximab before and during coronary intervention in refractory unstable angina: The CAPTURE Study. Lancet 1997; 349: 1429-35.

20. Antman EM, Giugliano PR, Gibson CM, et al. Abciximab facilitates the rate and extent of thrombolysis: results of the thrombolysis in myocardial infarction (TIMI) 14 trial. Circulation 1999; 99: 2720-32.

21. Stone GW. Stenting in acute myocardial infarction: observational studies and randomized trials - 1998. I Invasive Cardiol 1998; 10(suppl A): 16A-26A
22. Rao AK, Pratt C, Berke A et al. Thrombolysis in myocardial infarction (TIMI) trial phase I: hemorragic manifestations and changes in plasma fibrinogen and the fibrinolytic system in patients treated with recombinant tissue plasminogen activator and streptokinase. J Am Coll Cardiol 1998; 11: 1-11.

23. The TIMI study group. The Thrombolysis in Myocardial Infarction (TIMI): phase I findings. N Eng J Med 1985; 312: 932-6.

24. Foley DP, Escaned J, Strauss BH, et al. Quantitative coronary angiography (QCA) in interventional cardiology: clinical application of QCA measurements. Progress Cardiovasc Dis 1994; 36: 363-84.

25. Kennedy JW, Sheehan FH. Ventriculografia. In: Pepine CJ, Hill JA, Lambert CR Cateterismo cardíaco: diagnóstico y terapéutica. $1^{\text {a }}$. ed. Buenos Aires: Editoria Médica Panamericana S.A., 1992: 154-66.

26. Sheehan FH, Bolson EL, Dodge HT, et al. Diagnostic methods: ventricular performance: advantages and application of the centerline method for characterizing regional ventricular function. Circulation 1986; 74: 293-305.

27. Karagounis L, Sorensen SG, Menlove RL, et al. Does thrombolysis in myocardial infarction (TIMI) perfusion grade 2 represent a mostly patent artery or a mostly occluded artery?: enzymatic and electrocardiographic evidence from the TEAM-2 study. J Am Coll Cardiol 1992; 19: 1-10.

28. The GUSTO IIb Angioplasty Substudy Investigators. A clinical trial comparing primary coronary angioplasty with tissue plasminogen activator for acute myocardial infarction. NEng J Med 1997; 336: 1621-8

29. Grines CL, Cox DA, Stone GW, et al. Coronary angioplasty with or without sten implantation for acute myocardial infarction. NEng J Med 1999; 341: 1949-56.

30. Muhlestein JB, Karagounis LA, Treehan S, Anderson JL. "Rescue" utilization of abciximab for the dissolution of coronary thrombus developing as a complication of coronary angioplasty. J Am Coll Cardiol 1997; 30: 1729-34.

31. Gold HK, Garabedian HD, Dinsmore R, et al. Restoration of coronary flow in myocardial infarction by intravenous chimeric 7E3 antibody without exogenous plasminogen activators : observations in animals and humans. Circulation 1997; 95: 1755-9.

32. Lemos JA, Antman E, Gibson M, et al. Abciximab improves both epicardial flow and myocardial reperfusion in ST-elevation Myocardial infarction : observations from the TIMI 14 trial. Circulation 2000; 101: 239-43.

33. Lincoff AM, Topol EJ. Illusion of reperfusion: does anyone achieve optimal reperfusion during acute myocardial infarction? Circulation 1993; 88: 1361-74.

34. Ito H, Tomooka T, Sakai N, et al. Lack of myocardial perfusion immediately afte successful thrombolysis: a predictor of poor recovery of left ventricular function in anterior myocardial infarction. Circulation 1992; 85: 1699-705.

35. Sakuma T, Hayashi Y, Sumii K, et al. Prediction of short and intermediate-term prognosis of patients with acute myocardial infarction using myocardial contrast echocardiography one day after recanalization. J Am Coll Cardiol 1998; 32 890-7.

36. Porter TR, LiS, Oster R, et al. The clinical implications of no reflow demonstrated with intravenous perfluorocarbon containing microbubbles following restoration of thrombolysis in myocardial infarction (TIMI) 3 flow in patients with acute myocardial infarction. Am J Cardiol 1998; 82: 1173-7.

37. Neumann FJ, Blasini R, Schmitt C, et al. Effect of Glycoprotein IIb/IIIa recepto blockade on recovery of coronary flow and left ventricular function after the placement of coronary-artery stents in acute myocardial infarction. Circulation 1998; 98: 2695-701

38. Califf RM, Harrelson-Woodlief L, Topol EJ.Left ventricular ejection fraction may not be useful as na end point of thrombolytic therapy comparative trials. Circulation 1990; 82: 1847-53.

39. Azar RR, McKay RG, Thompson PD, et al. Abciximab in primary coronary angioplasty for acute myocardial infarction improves short and medium term outcomes. J Am Coll Cardiol 1998; 32: 1996-2002.

40. Munhoz EC, Oliveira PF. Significado clínico da reoclusão hospitalar no infarto agudo do miocárdio tratado com reperfusão mecânica e angioplastia coronariana primária. Arq Bras Cardiol 2000; 75: 429-35.

41. Ribeiro EE, Petrizzo A, Carneiro R, et al. Quais os resultados imediatos e tardios da angioplastia coronária primária? Rev Soc Cardiol Estado de São Paulo 2000 10: $225-36$ 